\title{
Duality and complexity of allergic type inflammatory mechanisms in determining the outcome of malaria disease
}

\author{
Ulrich Blank ${ }^{1,2}$ and Salaheddine Mécheri ${ }^{3}$ * \\ 1 INSERM U699, Paris, France \\ ${ }^{2}$ Faculté de Médecine Paris Diderot - Site Xavier Bichat, UMR-S699, Université Paris Diderot-Paris 7, Paris, France \\ ${ }^{3}$ Unité de Biologie des Interactions hôte-parasite, Department of Parasitology and Mycology, Institut Pasteur, Paris, France
}

\section{Edited by:}

Toshiaki Kawakami, La Jolla Institute for Allergy and Immunology, USA

Reviewed by:

Takayuki Yoshimoto, Tokyo Medical University, Japan

Arnaud Hot, Hopital Edouard Herriot France

\section{${ }^{*}$ Correspondence:}

Salaheddine Mécheri, Unité de

Biologie des Interactions

hôte-parasite, Institut Pasteur, 28 rue

du Dr Roux, Paris 75724 Cedex 15,

France.

e-mail: smecheri@pasteur.fr
One of the effector arms of the pathogenesis of severe forms of malaria disease is the development of uncontrolled or excessive inflammatory responses. A characteristic inflammatory response may arise from the propensity of some individuals to produce $\lg \mathrm{E}$ antibodies against environmental antigens or against parasite components. We believe that an allergic inflammatory response which develops concomitantly with a malaria episode may drive the disease course toward severe forms. The role of the $|g E-F c \varepsilon R|$ complex in malaria severity in Plasmodium falciparum-hosting patients is unknown. Subsequently, except a very limited number of reports, study of effector cells that express this complex such as mast cells and basophils and that may contribute to malaria pathogenesis have been particularly neglected. A better understanding of this type of inflammatory response and its implication in malaria disease and how it impacts Plasmodium parasite development may provide additional tools to alleviate or to cure this deadly disease.

Keywords: IgE, Fc\&RI, basophils, mast cells, malaria, Plasmodium

\section{INTRODUCTION}

Natural immunity to malaria is usually acquired slowly and its maintenance requires repeated parasite exposures (Greenwood, 1999). This immunity reduces the risk of both severe and mild malaria but does not diminish parasitemia. The defense mechanisms require cooperation between antibodies $(\mathrm{Ab})$ and cellular immune responses (Bouharoun-Tayoun et al., 1995). Antibodydependent mechanisms have been clearly shown to play an important role in the anti-parasite immunity and can reduce clinical symptoms in humans, as demonstrated by the positive effect of hyperimmune immunoglobulin $\mathrm{G}(\operatorname{IgG})$ passively transferred to infected patients (Bouharoun-Tayoun et al., 1990; Plebanski and Hill, 2000). IgE levels and IgE anti-plasmodial Ab are elevated in human and experimental malaria infections, but their role in protection and/or pathogenesis in malaria is still controversial (Desowitz, 1989; Perlmann et al., 1994; Troye-Blomberg et al., 1999). According to these authors, adults, and children living in malaria-endemic areas in different African and Asian countries including Liberia, The Gambia, Madagascar, and Thailand $85 \%$ of the donors had significantly elevated levels of IgE and more than $60 \%$ of these had detectable antimalarial specific IgE antibodies as compared to healthy and atopic SWEDISH donors (Perlmann et al., 1994).

The most important and widely investigated biological functions of IgE are anti-parasite immunity, especially against nematodes, and IgE-mediated allergic responses. It is believed that uncontrolled inflammatory responses are a characteristic feature of the pathogenetic mechanisms of severe forms of malaria. We became interested in exploring the role of IgE-mediated inflammatory response in malaria disease such as cerebral malaria (CM). In the present review, we will discuss data from several immuno-epidemiological human studies in various geographical areas as well as data from experimental studies using a murine model of CM.

\section{ROLE OF IgE IN MALARIA INFECTION AND DISEASE}

Assessment of the antibody response against Plasmodium falciparum blood stages determined in individuals naturally exposed to malaria in endemic areas of Brazil shows that the highest levels of IgG1, IgG2, and IgG3 antibodies were observed in individuals with asymptomatic and uncomplicated malaria, while highest levels of IgG4, IgE, and IgM antibodies were predominant among individuals with complicated malaria (Leoratti et al., 2008). These results are in agreement with those of other investigators who demonstrated that Plasmodium-specific IgG1 and IgG3 antibodies have a protective role against malaria, while $\lg G 4$ antibodies very likely do not protect against the disease (Sarthou et al., 1997; Taylor et al., 1998; Tangteerawatana et al., 2001, 2007). A consistent observation, however, indicate that high overall levels of IgE have been found in populations exposed to malaria (Perlmann et al., 1994) in $94 \%$ of the individuals studied. However, there is some controversy as to the role of specific IgE antibodies and whether they serve to protect against the disease or to make the illness more severe.

Several findings suggest that $\operatorname{IgE}$ could play a detrimental role during malaria disease development. This was supported by data showing that IgE levels were reduced amongst patients with uncomplicated malaria in comparison to those suffering from 
severe malaria (Perlmann et al., 1994, 1997, 2000; Seka-Seka et al., 2004). Furthermore, immunohistological studies on brain sections revealed the presence of IgE deposits in brain microvessels and on infected erythrocytes from CM patients as well as in placentas infected with P. falciparum (Maeno et al., 1993, 2000). Various immune complexes (ICs), which consist of either IgE and antigen aggregates or IgE with IgG anti-IgE, could bind to Fc receptors expressed on monocytes which become activated giving rise to TNF- $\alpha$ secretion (Elghazali et al., 1997; Perlmann et al., 1999). Although TNF- $\alpha$ may play a protective role against the parasites, elevated levels in the blood were related to worsening of the disease and death in cases of severe malaria (Grau et al., 1989; Kwiatkowski et al., 1990). In addition, IgE levels were found to be higher in cerebral $P$. falciparum malaria when compared to uncomplicated malaria (Desowitz, 1989; Luty et al., 1994). Among patients with severe malaria, the increase in IgE levels was related to the deepness of the coma (Maeno et al., 2000).

In the opposite, other evidence could support the notion that specific IgE antibodies provide protection against malaria: (a) IgE levels increase with age which determines the acquisition of immunity (Desowitz et al., 1993; Maeno et al., 1993); (b) high concentration of IgE antibodies against $P$. falciparum were lower in the comatose patients than in the non-comatose patients (Calissano et al., 2003); (c) A study carried out in the ethnic group Fulani, known to be less susceptible to malaria infections, revealed that the Fulani were less parasitized, had fewer circulating parasite clones in their blood, and had significantly higher anti-malaria IgG and IgE antibodies as well as higher proportions of malaria-specific IL4- and IFN- $\gamma$-producing cells compared to the more susceptible Dogon individuals (Farouk et al., 2005); (d) a study in Tanzania has shown that elevated levels of malaria-specific IgE reduces the risk of subsequent malaria attacks (Bereczky et al., 2004); (e) More recently, antigen-specific IgE antibodies in asymptomatic and uncomplicated malaria patients were found to be higher than in severe or CM groups (Duarte et al., 2007).

Among the reasons that account for these apparently antagonistic roles of IgE in malaria disease are, of course, the genetic diversity of human populations involved in the different studies, but also and more importantly the concomitant infections, diseases, or even silent carriage of microorganisms. As will be discussed below, in addition to a number of polymorphisms in host genes, one single infected individual may harbor a diversity of genetically different Plasmodium parasites, hence increasing the number of variables that need to be controlled for a better appreciation on whether and how IgE response determines the outcome of malaria disease.

Antibodies of various isotypes can exert their effector function as soluble monomeric form or as ICs bound either to antigens or to autoantibodies. Children with severe malaria-associated anemia and CM had significantly higher IC levels than their respective controls suggesting a possible role for ICs in the pathogenesis of CM (Adam et al., 1981; Mibei et al., 2005). However, albeit ICs may be involved in the pathogenesis of these two clinical presentations, they alone cannot explain their distinct clinical manifestations. Moreover, children developing CM may be more susceptible to IC-mediated inflammatory response occurring in the brain or there may be qualitative rather than quantitative differences in ICs between these groups that could further impact on the clinical presentation. In a study performed in Kenya, levels of IgE-containing ICs were higher in children with CM than in their controls and were the only independent predictors of CM at enrollment (Mibei et al., 2008). In support of the role of ICs in the pathogenesis of $\mathrm{CM}, \mathrm{IgE}$ deposits found in the brain obtained from CM fatalities may induce TNF- $\alpha$ (Clark and Cowden, 1992) from activated monocytes (Perlmann et al., 1999) or alternatively, induce mediator release such as histamine from stimulated basophils or mast cells.

Several evidences indicate that basophils might represent effector cells by regulating the Th1/Th2 balance, which may affect the outcome of malaria disease. Evidence has been provided supporting the role of basophils in the polarizing capacity toward Th2 cells in the murine Plasmodium chabaudi chabaudi system. Here, it has been shown that a population of IL-3 responsive IL-4 producing non-B non-T (NBNT) cells of basophil origin expand in the spleen and in the peripheral blood during acute infection (Poorafshar et al., 2000). Other evidences show that IgE antibodies that form ICs were potent inducers of IL-4 in human basophils, potentially regulating the switch from Th1 to Th2 cells (Nyakeriga et al., 2003). However, no functional relationship between increased number of basophils and their potential activation by IgE ICs and the disease severity could be formally established. Very recently, we found that in a murine model of CM, specific depletion of basophils using the Ba103 antibody did not result in any change of the phenotype of the C57BL/6 mice regarding the development of CM (Porcherie et al., 2011).

\section{GENETIC LINIKAGE STUDIES: CONTROL OF MALARIA DISEASE BY ALLERGIC RESPONSE-ASSOCIATED GENES A REGION OF THE CHROMOSOME $5 q 31$ IS ASSOCIATED WITH MALARIA SUSCEPTIBILITY}

Genome wide association studies (GWAS), which allows the identification of genetic factors underlying phenotypic traits, revealed several genes involved in infection and/or malaria disease severity. Thus, a number of studies have provided evidence that a genome region, 5q31-33, that contains a cluster of genes encoding cytokine and growth factors was found to be significantly linked to malaria parasite density (Rihet et al., 1998), and involved in the control of immunity to $P$. falciparum blood stage (Troye-Blomberg et al., 1994). In another longitudinal survey carried out independently for Dielmo and Ndiop, two Senegalese villages that differ in parasite transmission and endemicity, parasite density showed linkage to a region on chromosome 5q31 (Sakuntabhai et al., 2008) previously identified to overlap with those that have been shown to be linked to asthma/atopy related traits and to elevated IgE levels. The importance of this region in immune regulation is highlighted by its linkage to plasma IgE levels (Marsh et al., 1994; Meyers et al., 1994), bronchial hyperresponsiveness (Postma et al., 1995), and to Schistosoma mansoni infection intensity (Marquet et al., 1996) in humans and with resistance to $P$. chabaudi in mice (Hernandez-Valladares et al., 2004). Several genes encoding mostly TH2 cytokines, IL-13, IL-4, IL-5, IL-9, IL-3, but also the Th1 cytokine IL-12B, are clustered in the 5q31-33 region and may represent strong candidates for controlling the outcome of infection or malaria disease. It is therefore interesting to explore 
genes in the $5 q 31$ region for identifying variants associated with susceptibility or resistance to severe malaria.

\section{ASSOCIATION OF Th2 CYTOKINE GENE POLYMORPHISMS WITH SEVERE MALARIA \\ IL-4 polymorphism}

The gene for IL-4, a pleiotropic cytokine promoting antibody IgE isotype switching, lies altogether with other Th2 cytokine genes in the 5 q31 region previously shown to be linked to $P$. falciparum infection (Rihet et al., 1998). A study in Burkina Faso has shown that an allelic variant $-589 \mathrm{~T}$ in the promoter region of IL-4 is associated in the Fulani with higher levels of antibodies to several $P$. falciparum antigens (Luoni et al., 2001). The proportions of $P$. falciparum-induced IL-4, IFN- $\gamma$, IL-10, and IL-12 producing cells, were compared between Fulani and Dogon from Mali. Both IFN$\gamma$ (Th1) and IL-4 (Th2) producing cells were present in higher numbers in Fulani than in Dogon, which suggests that the Fulani resistance to malaria is not mediated by a Th2 polarized immune response, it could be more likely the result of a generally stronger immune activation or weaker immune suppression.

Further investigations were carried out in the attempt to correlate this IL-4 allelic variant with disease severity within a casecontrol study in Burkina Faso (Verra et al., 2004), and another case-control study in Ghana (Gyan et al., 2004). The former study showed no difference in allele frequency between severe malaria cases and uncomplicated malaria patients; however, within severe malaria cases higher total IgE levels were observed in both homozygous and heterozygous IL-4-589T carriers. Moreover, the latter study revealed higher total IgE levels in CM cases carrying the IL-4-589T allelic variant.

\section{IL-13 polymorphism}

The switch recombination of immunoglobulins to the IgE isotype requires two signals from activated $T$ cells: the up-regulation of the CD40 ligand and the secretion of IL-4 or IL-13. Both IL-4 and IL-13, independently of each other, are able to induce IgE antibody production (Punnonen et al., 1993). Induction of CD23 expression on B cells is another shared activity between IL-4 and IL-13 (Punnonen et al., 1993). An initial study performed in patients that live in Northwest Thailand has demonstrated that a single nucleotide polymorphism (SNP) in the $I L-13$ promoter region was found to be associated with susceptibility to severe malaria (Ohashi et al., 2003). In a more recent study, this SNP was found to be included in a haplotype block on chromosome $5 \mathrm{q} 31$ encompassing the whole $R A D 50$ gene and the promoter of the $I L-13$ gene (Naka et al., 2009). RAD50 itself, which is part of a multiprotein complex that is involved in B cell-specific immunoglobulin gene diversification (Yabuki et al., 2005), may influence affinity or effector functions of antibodies. More recently, polymorphisms within the RAD50 gene were consistently associated with IgE levels and increased the risk for atopic eczema and asthma (Weidinger et al., 2008).

\section{OTHER GENES}

\section{CD154 polymorphism}

CD40 ligand (CD40L), a glycoprotein involved in B cell proliferation, antigen presenting cell activation, and Ig isotype switching plays a pivotal role in the immune response to infection. Besides signals provided by IL-4, engagement of CD40 expressed by B cells by the CD40 ligand (CD40L) expressed on activated T cells leads to switching to IgE isotype during immunoglobulin synthesis in $\mathrm{B}$ cells. To identify CD40L polymorphisms associated with malaria severity, Gambian males that are hemizygous for CD40L-726C exhibit significant protection against $\mathrm{CM}$ and severe malarial anemia (Sabeti et al., 2002). A polymorphism in the promoter region, CD40L-726T/C, was tested for association with malaria in a casecontrol study in The Gambia revealing a significant association of the CD40L-726C allele with severe malaria, both severe anemia and $\mathrm{CM}$, in hemizygous (X-linked trait) males.

\section{Haptoglobin}

A hemoglobin binding protein, is another candidate gene for which the polymorphism pattern has been explored to establish an association between past malaria morbidity and atopic diseases. Amongst the malaria patients, the haptoglobin Hp1/1 phenotype was significantly more prevalent for patients showing the complications of CM and severe anemia compared to patients with uncomplicated disease (Quaye et al., 2000). A study conducted in atopic children living in Sardinia showed that the Hp1/1 genotype which was expressed at higher frequency in populations subjected to high malarial endemia also showed a higher incidence in patients with atopic diseases than in control population (Bottini et al., 1999). Hp 1/1 was shown to be overrepresented in atopic asthma (Bottini et al., 1999) but also in allergic contact dermatitis and allergic rhinitis (Langlois and Delanghe, 1996).

\section{Neutrophil-associated genes}

The role of neutrophil activation in the host response to $P$. falciparum remains under-investigated. Host resistance to malarial infection is not classically attributed to a neutrophil response (Stevenson and Riley, 2004). However, examining gene-expression profiles in whole blood from Kenyan children, Griffiths et al. (2005) identified a cluster associated with neutrophil activity, including absolute neutrophil count and neutrophil-related geneexpression. A significant increase in gene-expression intensity corresponded to a significant increase in neutrophil count in subjects who had acute malaria as compared to convalescent subjects. Indeed, it has been observed that neutrophilia has been linked with acute malaria (Ladhani et al., 2002). However, the effector mechanisms by which neutrophils contribute to malaria pathogenesis remain to be explored.

\section{EFFECTOR MECHANISIMS OF ALLERGIC RESPONSE INVOLVED IN MALARIA PATHOGENESIS}

In humans, studies aiming at establishing the allergic nature of malaria disease report conflicting results ranging from diseaseaggravating to disease-protecting roles of IgE (Perlmann et al., 1997; Bereczky et al., 2004). To clarify this issue, we used genetically deficient animals or antibody-depleted cell populations to examine crucial components of the allergic inflammatory response in malaria pathogenesis. To this aim, we used a murine model of CM which relies on the infection of a susceptible C57BL/6 mouse strain with the $P b A N K A$ parasite strain. Neurological signs followed by death occur between 6 and 11 days post-infection. 


\section{ROLE OF HISTAMINE AND HISTAMINE RECEPTORS IN MALARIA PATHOGENESIS}

We previously reported that Anopheles stephensi mosquito bites result in a local IgE-independent degranulation of skin mast cells as assessed by a rapid dermal inflammation and the hyperplasia of the draining lymph nodes (Demeure et al., 2005). This provided a mechanism whereby mosquito bites may shape the immune response to sporozoites present in their saliva and inoculated during the blood meal. The sites of mosquito bites are characterized by fluid extravasation and rapid infiltration with polynuclear neutrophils. This rapid onset of inflammatory responses led us to hypothesize that histamine release may represent one of the mechanisms that facilitates parasite transmission during inoculation by infected Anopheles mosquitoes. Indeed, increased levels of histamine in plasma and tissue, were found to be associated with the severity of disease in humans infected with P. falciparum and in several animal models of infections with Plasmodium (Maegraith and Fletcher, 1972; Srichaikul et al., 1976; Bhattacharya et al., 1988). The increase in vascular permeability appears to be a component of malaria pathogenesis and could be advantageous for the parasites, as sporozoites or blood stage parasites, since it facilitates their entry and exit from blood vessels. The vasodilatory effects of histamine might promote spread of the parasite through the vasculature.

Based on divergent approaches using $\mathrm{H}_{1} \mathrm{R}^{-1-}$ and $\mathrm{H} 2 \mathrm{R}^{-1-}$ mice, anti-histamine drugs, and histamine-deficient mice, we demonstrated that histamine signaling was associated with the severity of disease (Beghdadi et al., 2008). Mice genetically deficient in $\mathrm{H} 1 \mathrm{R}$ and $\mathrm{H} 2 \mathrm{R}$ as well as mice treated with $\mathrm{H} 1$ and $\mathrm{H} 2$ anti-histamines revealed a delayed mortality as compared to similarly infected wild-type mice that had not been treated with anti-histamines. This suggests that production and binding of histamine to these two receptors are deleterious to the host (Beghdadi et al., 2008). Unequivocal implication of histamine in malaria pathogenesis was provided by the use of histidine decarboxylase-knock out $\left(\mathrm{HDC}^{-1-}\right)$ mice which did not develop neuropathology in contrast to wildtype mice (Beghdadi et al., 2008). Histamine production can be elicited from circulating basophils either via cross-linking of parasite-specific IgE antibodies or by the translationally controlled tumor protein (TCTP), a parasite-derived homolog of the histamine releasing factor (HRF). TCTP has been found in the plasma of patients infected with $P$. falciparum and was shown to trigger histamine release from basophils and IL8 secretion from eosinophils (MacDonald et al., 2001). The existence of a Plasmodium protein that stimulates histamine release lends support to the hypothesis that histamine signaling is advantageous to the parasite, and thus harmful to the host. These findings could provide a rational basis for higher levels of histamine in blood and in tissues during malaria as a result of the activity of vector- or parasite-derived constituents. Amplifying the host inflammatory response, via histamine signaling, may be a strategy developed by the parasites to create conditions advantageous for their own survival and persistence.

\section{IMPLICATION OF NEUTROPHILS EXPRESSING UNCONVENTIONAL FC\&RI IN ELICITING SEVERE MALARIA}

We found that targeted disruption of IgE or the $\alpha$ chain of FceRI led to resistance to the development of ECM after infection with PbANKA (Porcherie et al., 2011). These results indicate a pathological role of IgE that acts via FceRI to promote disease development. The association of FceRI with the neuropathological disorders observed during ECM was further emphasized by the constant increase of receptor $\alpha$ chain mRNA expression in the brain of infected mice. Conventional effector cells expressing FceRI in mice consist of MCs and basophils. Interestingly however, our data using MC-deficient mice or antibody-mediated depletion of basophils excluded MCs and basophils as relevant effector cells (Porcherie et al., 2011). They also did not show beneficial actions of MCs in contrast to previous data, which reported that MCs and MC-derived TNF- $\alpha$ protect against ECM (Furuta et al., 2006). This contradictory result may have been influenced by the different MC-deficient $\mathrm{W} / \mathrm{W}^{\mathrm{v}}$ mouse strain used, which makes the mice anemic, and thus potentially compromised in controlling a parasite infection. It was also puzzling that TNF- $\alpha$ was protective in this study, although TNF- $\alpha$ generally enhances disease severity (Grau et al., 1987). Searching for alternative FcERI-expressing cell types, we identified neutrophils and eosinophils, and discovered that the former had a disease enhancing capacity (Porcherie et al., 2011). Although FceRI $\alpha$ is essentially absent in neutrophils in naive mice, we found that it becomes induced during Plasmodium infection as demonstrated by the increase in expression of $\alpha$ chain mRNA using RT-PCR analysis, the binding of the $\alpha$ chainspecific MAR-1 antibody, and detection of membrane-bound IgE. Attempts to characterize the biochemical nature of this receptor on neutrophils showed that the receptor was colocalized with the FceRI $\gamma$ subunit that could be coimmunoprecipitated with IgE. In contrast, the FceRI $\beta$ chain was undetectable in neutrophils (Porcherie et al., 2011). Although expression of the receptor in the absence of FceRI $\beta$ has never been demonstrated before in mice (Miller et al., 1989), in humans FceRI is frequently expressed in several hematopoietic cells including monocytes, eosinophils, and neutrophils of atopic asthmatics as a trimeric FceRI $\alpha \gamma 2$ receptor (Saffar et al., 2007), whereas it is absent in healthy individuals. It has therefore been postulated that FceRI-induced inflammatory signaling and the reported antiapoptotic effect of monomeric IgE may exacerbate the pathogenetic effects of $\mathrm{FccRI}^{+}$neutrophils in asthma (Saffar et al., 2007). A parallel can be made in the present work as to the possible implication of $\mathrm{F}_{c \varepsilon R \mathrm{RI}^{+}}$neutrophils in malaria pathogenesis. The evidence for that was that transfer of ${\mathrm{F} c \varepsilon R I^{+}}^{+}$, but not FceRI ${ }^{-}$, neutrophils conferred ECM susceptibility to the otherwise resistant FceRI- $\alpha-\mathrm{KO}$ mice (Porcherie et al., 2011). Furthermore, this sub-population was specifically enhanced in the brain during ECM development. These results emphasize the critical role of $\mathrm{FccRI}^{+}$neutrophils in the disease expression and mortality, as the sequestration properties of this cell population in the brain tissue occurs rapidly, within an hour after cell transfer, in PbANKA-infected FceRI- $\alpha-\mathrm{KO}$ mice that are otherwise CM resistant.

Several questions remain unresolved. In particular, the Plasmodium infection-associated signals required for the induction 


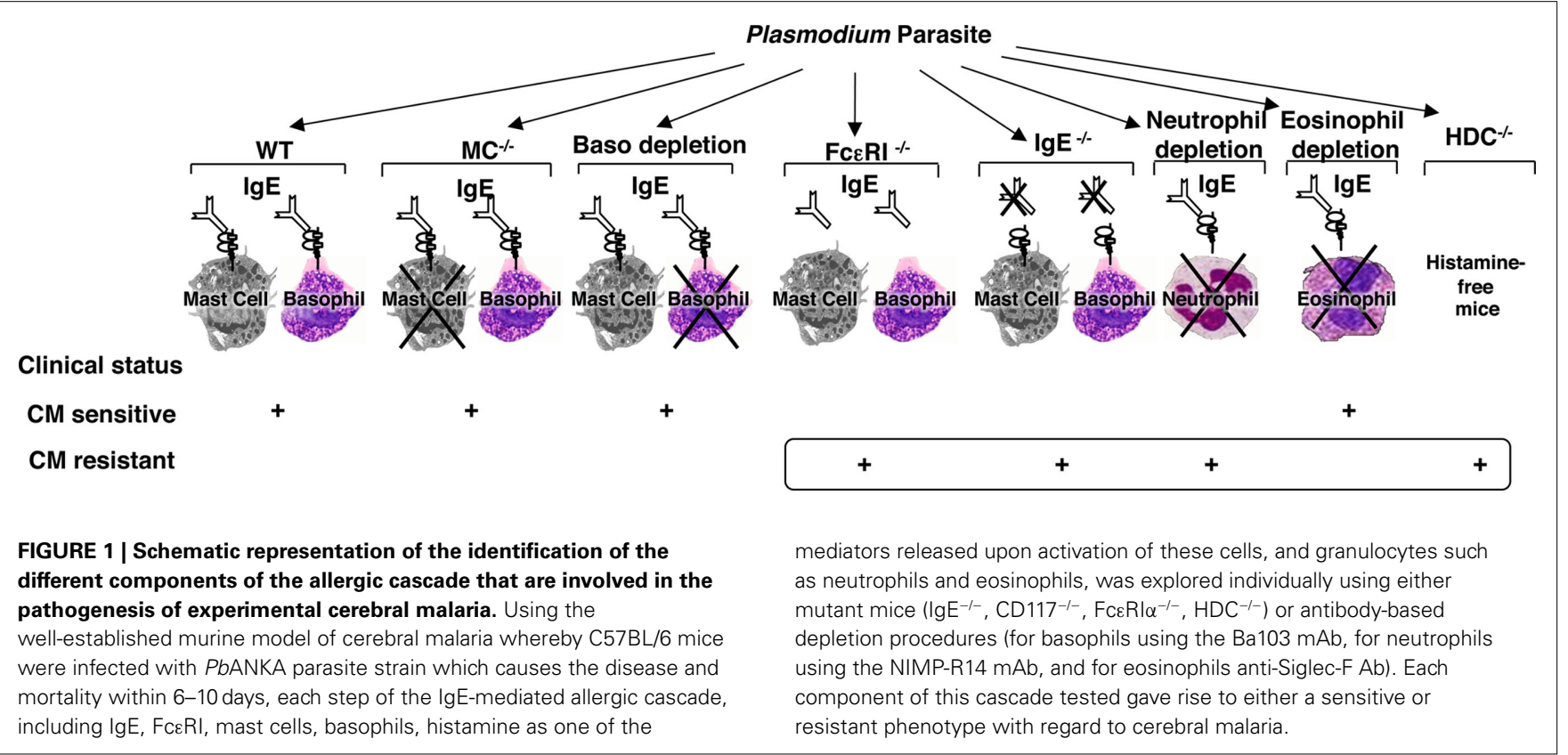

of FceRI expression in neutrophils are unknown. However, this property seems to be specific to the ECM-inducing PbANKA parasite, as mice infected with non-ECM-inducing $P b N K 65$ parasite or mice infected with Escherichia coli undergoing septic peritonitis as a result of cecal ligation and puncture did not show any expression of FceRI in their neutrophils (Porcherie et al., 2011). However, a precedent for the expression of FceRI in the absence of FceRI $\beta$ in mice has previously been made in lung DCs after infection with Sendai virus (Grayson et al., 2007). It is therefore conceivable that infectious events may enable expression of a trimeric FceRI $\alpha \gamma 2$ receptor by masking inherent retention signals of the $\alpha$ chain (Blank et al., 1991; Hartman et al., 2008). Alternatively, they may induce expression of " $\beta$-like" molecules that support receptor expression. Additional studies are necessary to clarify the various aspects leading to the activation of $\mathrm{Fc}_{\mathrm{C}} \mathrm{RI}^{+}$neutrophils during malaria disease.

\section{CONCLUSION}

Undesirable inflammatory responses are often involved in the pathogenesis of many diseases. Therefore, it was legitimate to ask whether IgE-mediated allergic inflammatory response in atopic individuals living in endemic areas may predispose this particular population to develop severe forms of malaria disease such as severe anemia and CM. As discussed in this review, many prominent groups have investigated this issue using essentially immunoepidemiological tools as well as genetic approaches. As cause-andeffect relationship between IgE response and disease outcome is

\section{REFERENCES}

Adam, C., Geniteau, M., and GougerotPocidalo, M. (1981). Cryoglobulins, circulating immune complexes, and complement activation in cerebral malaria. Infect. Immun. 31, 530-535.
Beghdadi, W., Porcherie, A., Schneider, B. S., Dubayle, D., Peronet, R., Huerre, M., Watanabe, T., Ohtsu, H., Louis, J., and Mecheri, S. (2008). Inhibition of histamine-mediated signaling con-

difficult to achieve, there are still questions as to whether allergic diseases represent aggravating conditions for malaria.

Although animal models of malaria disease and infection do not perfectly match the human situation, they are still informative in terms of exploring and understanding the basic mechanisms. To this aim, we designed a comprehensive and integrated approach where each step of the IgE-mediated allergic inflammatory cascade has been assessed for its possible implication in the disease pathogenesis in a well-established murine model of CM (Figure 1).

Collectively, our findings provide a new concept on inflammatory response-driven malaria pathogenesis where neutrophils play a central role in inducing allergic type reactions, implicated in the development of ECM. In particular, we identified a novel sub-population of neutrophils expressing the FceRI, exclusively induced during a malaria parasite infection resulting in CM. Although the involvement of neutrophils in malaria pathology is now established, the effector mechanisms whereby the inducible $\mathrm{FcERI}^{+}$neutrophil population contributes to the disease pathogenesis remain unresolved. Whilst it is well-established that the inflammatory response plays a decisive role in malaria pathogenesis, the concept that neutrophils play a key role in this adds a new piece to the pathogenic puzzle underlying malaria disease. One of the possible implications of this seminal work in a mouse model of $\mathrm{CM}$ will be to establish its relevance to the human condition. Moreover, mutations in Fc\&RI have been associated with asthma and their relevance for severe outcome of Plasmodium infections deserves to be addressed in the future.

fers significant protection against severe malaria in mouse models of disease. J. Exp. Med. 205, 395-408.

Bereczky, S., Montgomery, S. M., TroyeBlomberg, M., Rooth, I., Shaw, M.
A., and Farnert, A. (2004). Elevated antimalarial IgE in asymptomatic individuals is associated with reduced risk for subsequent clinical malaria. Int. J. Parasitol. 34, 935-942. 
Bhattacharya, U., Roy, S., Kar, P. K., Sarangi, B., and Lahiri, S. C. (1988). Histamine \& kinin system in experimental malaria. Indian J. Med. Res. 88, 558-563.

Blank, U., Ra, C. S., and Kinet, J. P. (1991). Characterization of truncated alpha chain products from human, rat, and mouse high affinity receptor for immunoglobulin E. J. Biol. Chem. 266, 2639-2646.

Bottini, N., Ronchetti, M. P., GloriaBottini, F., and Fontana, L. (1999). Malaria as possible evolutionary cause of allergy. Allergy 54, 188-189. Bouharoun-Tayoun, H., Attanath, P., Sabchareon, A., Chongsuphajaisiddhi, T., and Druilhe, P. (1990). Antibodies that protect humans against Plasmodium falciparum blood stages do not on their own inhibit parasite growth and invasion in vitro, but act in cooperation with monocytes. J. Exp. Med. 172, 1633-1641.

Bouharoun-Tayoun, H., Oeuvray, C., Lunel, F., and Druilhe, P. (1995). Mechanisms underlying the monocyte-mediated antibody killing of Plasmodium falciparum asexual blood stages. J. Exp. Med. $182,409-418$.

Calissano, C., Modiano, D., Sirima, B. S., Konate, A., Sanou, I., Sawadogo, A., Perlmann, H., Troye-Blomberg, M., and Perlmann, P. (2003). IgE antibodies to Plasmodium falciparum and severity of malaria in children of one ethnic group living in Burkina Faso. Am. J. Trop. Med. Hyg. 69, 31-35.

Clark, I. A., and Cowden, W. B. (1992). Roles of TNF in malaria and other parasitic infections. Immunol. Ser. 56, 365-407.

Demeure, C. E., Brahimi, K., Hacini, F., Marchand, F., Peronet, R., Huerre, M., St-Mezard, P., Nicolas, J. F., Brey, P., Delespesse, G., and Mecheri, S. (2005). Anopheles mosquito bites activate cutaneous mast cells leading to a local inflammatory response and lymph node hyperplasia. J. Immunol. 174, 3932-3940.

Desowitz, R. S. (1989). Plasmodium falciparum immunoglobulin $\mathrm{E}$ in sera from an area of holoendemic malaria. Trans. R. Soc. Trop. Med. Hyg. 83, 478-479.

Desowitz, R. S., Elm, J., and Alpers, M. P. (1993). Plasmodium falciparum Specific immunoglobulin G (IgG), $\operatorname{IgM}$ and $\operatorname{IgE}$ antibodies in paired maternal-cord sera from East Sepik Province, Papua New Guinea. Infect. Immun. 61, 988-993.

Duarte, J., Deshpande, P., Guiyedi, V., Mécheri, S., Fesel, C., Cazenave, P.A., Mishra, G. C., Kombila, M., and
Pied, S. (2007). Total and functional parasite specific IgE responses in Plasmodium falciparum-infected patients exhibiting different clinical status. Malar. J. 6, 1-13.

Elghazali, G., Perlmann, H., Rutta, A. S., Perlmann, P., and TroyeBlomberg, M. (1997). Elevated plasma levels of IgE in Plasmodium falciparum-primed individuals reflect an increased ratio of IL-4 to interferon-gamma (IFNgamma)-producing cells. Clin. Exp. Immunol. 109, 84-89.

Farouk, S. E., Dolo, A., Bereczky, S., Kouriba, B., Maiga, B., Farnert, A., Perlmann, H., Hayano, M., Montgomery, S. M., Doumbo, O. K., and Troye-Blomberg, M. (2005). Different antibody- and cytokinemediated responses to $P$. falciparum parasite in two sympatric ethnic tribes living in Mali. Microbes Infect. 7, 110-117.

Furuta, T., Kikuchi, T., Iwakura, Y., and Watanabe, N. (2006). Protective roles of mast cells and mast cellderived TNF in murine malaria. $J$. Immunol. 177, 3294-3302.

Grau, G. E., Fajardo, L. F., Piguet, P. F., Allet, B., Lambert, P. H., and Vassalli, P. (1987). Tumor necrosis factor (cachectin) as an essential mediator in murine cerebral malaria. Science 237, 1210-1212.

Grau, G. E., Taylor, T. E., Molyneux, M. E., Wirima, J. J., Vassalli, P., Hommel, M., and Lambert, P. H. (1989). Tumor necrosis factor and disease severity in children with falciparum malaria. N. Engl. J. Med. 320, 1586-1591.

Grayson, M. H., Cheung, D., Rohlfing, M. M., Kitchens, R., Spiegel, D. E., Tucker, J., Battaile, J. T., Alevy, Y., Yan, L., Agapov, E., Kim, E. Y., and Holtzman, M. J. (2007). Induction of high-affinity IgE receptor on lung dendritic cells during viral infection leads to mucous cell metaplasia. $J$. Exp. Med. 204, 2759-2769.

Greenwood, B. (1999). What can the residents of malaria endemic countries do to protect themselves against malaria? Parassitologia 41, 295-299.

Griffiths, M. J., Shafi, M. J., Popper, S. J., Hemingway, C. A., Kortok, M. M., Wathen, A., Rockett, K. A., Mott, R., Levin, M., Newton, C. R., Marsh, K., Relman, D. A., and Kwiatkowski, D. P. (2005). Genomewide analysis of the host response to malaria in Kenyan children. J. Infect. Dis. 191, 1599-1611.

Gyan, B., Goka, B., Cvetkovic, J. T., Kurtzhals, J. L., Adabayeri, V., Perlmann, H., Lefvert, A. K., Akanmori, B. D., and Troye-Blomberg,
M. (2004). Allelic polymorphisms in the repeat and promoter regions of the interleukin-4 gene and malaria severity in Ghanaian children. Clin. Exp. Immunol. 138, 145-150.

Hartman, M. L., Lin, S. Y., Jouvin, M. H., and Kinet, J. P. (2008). Role of the extracellular domain of Fc epsilon RI alpha in intracellular processing and surface expression of the high affinity receptor for $\mathrm{IgE}$ Fc epsilon RI. Mol. Immunol. 45, 2307-2311.

Hernandez-Valladares, M., Rihet, P., ole-MoiYoi, O. K., and Iraqi, F. A. (2004). Mapping of a new quantitative trait locus for resistance to malaria in mice by a comparative mapping approach with human chromosome 5q31-q33. Immunogenetics 56, 115-117.

Kwiatkowski, D., Hill, A. V., Sambou, I., Twumasi, P., Castracane, J., Manogue, K. R., Cerami, A. Brewster, D. R., and Greenwood, B. M. (1990). TNF concentration in fatal cerebral, non-fatal cerebral, and uncomplicated Plasmodium falciparum malaria. Lancet 336 1201-1204.

Ladhani, S., Lowe, B., Cole, A. O., Kowuondo, K., and Newton, C. R. (2002). Changes in white blood cells and platelets in children with falciparum malaria: relationship to disease outcome. Br. J. Haematol. 119, 839-847.

Langlois, M. R., and Delanghe, J. R. (1996). Biological and clinical significance of haptoglobin polymorphism in humans. Clin. Chem. 42, 1589-1600.

Leoratti, F. M. S., Durlacher, R. R., Lacerda, M. V. G., Alecrim, M. G., Ferreira, A. W., Sanchez, M. C. A., and Moraes, S. L. (2008). Pattern of humoral immune response to Plasmodium falciparum blood stages in individuals presenting different clinical expressions of malaria. Malar. J. 186, 1-11.

Luoni, G., Verra, F., Arca, B., Sirima, B. S., Troye-Blomberg, M., Coluzzi, M., Kwiatkowski, D., and Modiano, D. (2001). Antimalarial antibody levels and Il-4 polymorphism in the Fulani of West Africa. Genes Immun. 2, 411-414.

Luty, A. J. F., Mayombo, J., Lekoulou, F., and Mshana, R. (1994). Immunologic responses to soluble exoantigens of Plasmodium falciparum in Gabonese children exposed to continuous intense infection. Am. J. Trop. Med. Hyg. 51, 720-729.

MacDonald, S. M., Bhisutthibhan, J., Shapiro, T. A., Rogerson, S. J., Taylor, T. E., Tembo, M., Langdon, J. M., and Meshnick, S. R. (2001). Immune mimicry in malaria: Plasmodium falciparum secretes a functional histamine-releasing factor homolog in vitro and in vivo. Proc. Natl. Acad. Sci. U.S.A. 98, 10829-10832.

Maegraith, B., and Fletcher, A. (1972). The pathogenesis of mammalian malaria. Adv. Parasitol. 10, 49-75.

Maeno, Y., Perlmann, P., Perlmann, H., Kusuhara, Y., Taniguchi, K., Nakabayashi, T., Win, K., Looareesuwan, S., and Aikawa, M. (2000). IgE deposition in brain microvessels and on parasitized erythrocytes from cerebral malaria patients. Am. J. Trop. Med. Hyg. 63, 128-132.

Maeno, Y., Steketee, R., Nagatake, T., Tegoshi, T., Desowitz, R. S., Wirima, J. J., and Aikawa, M. (1993). Immunoglobulin complex deposits in Plasmodium falciparum-infected placentas from Malawi and Papua New Guinea. Am. J. Trop. Med. Hyg. 49, 574-580.

Marquet, S., Abel, L., Hillaire, D., Dessein, H., Kalil, J., Feingold, J., Weissenbach, J., and Dessein, A. J. (1996). Genetic localization of a locus controlling the intensity of infection by Schistosoma mansoni on chromosome 5q31-q33. Nat. Genet. 14, 181-184.

Marsh, D., Neely, J. D., Breazeale, D. R., Ghosh, B., Freidhoff, L. R., Ehrlich-Kautzky, E., Schou, C., Krishnaswamy, G., and Beaty, T. H. (1994). Linkage analysis of IL4 and other chromosome 5q31.1 markers and total serum immunoglobulin E concentrations. Science 264, 1152-1156.

Meyers, D. A., Postma, D. S., Panhuysen, C. I. M., Xu, J., Amelung, P. J., Levitt, R. C., and Bleecker, E. R. (1994). Evidence for a locus regulating total serum IgE levels mapping to chromosome 5. Genomics 23 , 464-470.

Mibei, E. K., Orago, A. S., and Stoute, J. A. (2005). Immune complex levels in children with severe Plasmodium falciparum malaria. Am. J. Trop. Med. Hyg. 72, 593-599.

Mibei, E. K., Otieno, W. O., Orago, A. S. S., and Stoute, J. A. (2008). Distinct pattern of class and subclass antibodies in immune complexes of children with cerebral malaria and severe malarial anaemia. Parasite Immunol. 30, 334-341.

Miller, L., Blank, U., Metzger, H., and Kinet, J. P. (1989). Expression of high-affinity binding of human immunoglobulin E by transfected cells. Science 244, 334-337. 
Naka, I., Nishida, N., Patarapotikul, J., Nuchnoi, P., Tokunaga, K., Hananantachai, H., Tsuchiya, N., and Ohashi, J. (2009). Identification of a haplotype block in the $5 \mathrm{q} 31$ cytokine gene cluster associated with the susceptibility to severe malaria. Malar. J. 8, 232-237.

Nyakeriga, M. A., Troye-Blomberg, M., Bereczky, S., Perlmann, H., Perlmann, P., and ElGhazali, G. (2003). Immunoglobulin E (IgE) containing complexes induce IL-4 production in human basophils: effect on Th1/Th2 balance in malaria. Acta Trop. 86, 55-62.

Ohashi, J., Naka, I., Patarapotikul, J., Hananantachai, H., Looareesuwan, S., and Tokunaga, K. (2003). A single-nucleotide substitution from $\mathrm{C}$ to $\mathrm{T}$ at position -1055 in the IL-13 promoter is associated with protection from severe malaria in Thailand. Genes Immun. 4, 528-531.

Perlmann, H., Helmby, H., Hagstedt, M., Carlson, J., Larsson, P. H., Troye-Blomberg, M., and Perlmann, P. (1994). IgE elevation and $\operatorname{IgE}$ anti-malarial antibodies in Plasmodium falciparum malaria: association of high IgE levels with cerebral malaria. Clin. Exp. Immunol. 97, 284-292.

Perlmann, P., Perlmann, H., ElGhazali, G., and Blomberg, M. T. (1999). IgE and tumor necrosis factor in malaria infection. Immunol. Lett. 65, 29-33.

Perlmann, P., Perlmann, H., Flyg, B. W., Hagstedt, M., Elghazali, G., Worku, S., Fernandez, V., Rutta, A. S., and Troye-Blomberg, M. (1997). Immunoglobulin E, a pathogenic factor in Plasmodium falciparum malaria. Infect. Immun. 65, 116-121.

Perlmann, P., Perlmann, H., Looareesuwan, S., Krudsood, S., Kano, S., Matsumoto, Y., Brittenham, G., Troye-Blomberg, M., and Aikawa, M. (2000). Contrasting functions of IgG and $\operatorname{IgE}$ antimalarial antibodies in uncomplicated and severe Plasmodium falciparum malaria. Am. J. Trop. Med. Hyg. 62, 373-377.

Plebanski, M., and Hill, A. V. S. (2000). The immunology of malaria. Curr. Opin. Immunol. 12, 437-441.

Poorafshar, M., Helmby, H., TroyeBlomberg, M., and Hellman, L. (2000). MMCP-8, the first lineagespecific differentiation marker for mouse basophils. Elevated numbers of potent IL-4-producing and MMCP-8-positive cells in spleens of malaria-infected mice. Eur. J. Immunol. 30, 2660-2668.

Porcherie, A., Mathieu, C., Peronet, R., Schneider, E., Claver, J., Commere, P. H., Kiefer-Biasizzo, H., Karasuyama, H., Milon, G., Dy, M., Kinet, J. P., Louis, J., Blank, U., and Mécheri, S. (2011). Critical role of the neutrophil-associated high-affinity receptor for IgE in the pathogenesis of experimental cerebral malaria. J. Exp. Med. 208, 2225-2236.

Postma, D. S., Bleeker, E. R., Amelung, P. J., Holroyd, K. J., Xu, J., Panhuysen, C. I., Meyers, D. A., and Levitt, R. C. (1995). Genetic susceptibility to asthma-bronchial hyperresponsiveness coinherited with a major gene for atopy. N. Engl. J. Med.333, 894-900.

Punnonen, J., Aversa, G., Cocks, B. G., McKenzie, A. N., Menon, S., Zurawski, G., de Waal Malefyt, R., and de Vries, J. E. (1993). Interleukin 13 induces interleukin 4independent IgG4 and IgE synthesis and CD23 expression by human B cells. Proc. Natl. Acad. Sci. U.S.A. 90, 3730-3734.

Quaye, I. K., Ekuban, F. A., Goka, B. Q., Adabayeri, V., Kurtzhals, J. A., Gyan, B., Ankrah, N. A., Hviid, L., and Akanmori, B. D. (2000). Haptoglobin 1-1 is associated with susceptibility to severe Plasmodium falciparum malaria. Trans. R. Soc. Trop. Med. Hyg. 94, 216-219.

Rihet, P., Traoré, Y., Abel, L., Aucan, C., Traoré-Leroux, T., and Fumoux, F. (1998). Malaria in humans: Plasmodium falciparum blood infection levels are linked to chromosome 5q31-q33. Am. J. Hum. Genet. 63, 498-505.

Sabeti, P., Usen, S., Farhadian, S., Jallow, M., Doherty, T., Newport, M., Pinder, M., Ward, R., and Kwiatkowski, D. (2002). CD40L association with protection from severe malaria. Genes Immun. 3, 286-291.

Saffar, A. S., Alphonse, M. P., Shan, L., Hayglass, K. T., Simons, F. E., and Gounni, A. S. (2007). IgE modulates neutrophil survival in asthma: role of mitochondrial pathway. $J$. Immunol. 178, 2535-2541.

Sakuntabhai, A., Ndiaye, R., Casadémont, I., Peerapittayamongkol, C., Rogier, C., Tortevoye, P., Tall, A., Paul, R., Turbpaiboon, C., Phimpraphi, W., Trape, J. F., Spiegel, A., Heath, S., Mercereau-Puijalon, O.,
Dieye, A., and Julier, C. (2008). Genetic determination and linkage mapping of Plasmodium falciparum malaria related traits in Senegal. PLoS ONE 3, e2000. doi:10.1371/journal.pone.0002000

Sarthou, J. L., Angel, G., Aribot, G., Rogier, C., Dieye, A., Balde, A. T., Diatta, B., Seignot, P., and Roussilhon, C. (1997). Prognostic value of anti-Plasmodium falciparum specific immunoglobulin G3, cytokines, and their soluble receptors in West Africa patients with severe malaria. Infect. Immun. 65, 3271-3276.

Seka-Seka, J., Brouh, Y., Yapo-Crezoit, A. C., and Atseye, N. H. (2004). The role of serum immunoglobulin $\mathrm{E}$ in the pathogenesis of $P$. falciparum malaria in Ivorian children. Scand. J. Immunol. 59, 228-230.

Srichaikul, T., Archararit, N., Siriasawakul, T., and Viriyapanich, T. (1976). Histamine changes in Plasmodium falciparum malaria. Trans. R. Soc. Trop. Med. Hyg. 70, 36-38.

Stevenson, M. M., and Riley, E. M. (2004). Innate immunity to malaria. Nat. Rev. Immunol. 4, 169-180.

Tangteerawatana, P., Krudsood, S., Chalermrut, K., Looareesuwan, S., and Khusmith, S. (2001). Natural human IgG subclass antibodies to Plasmodium falciparum blood stage antigens and their relation to malaria resistance in an endemic area of Thailand. Southeast Asian J. Trop. Med. Public Health 32, 247-254.

Tangteerawatana, P., Montgomery, S. M., Perlmann, H., Looareesuwan, S., Troye-Blomberg, M., and Khusmith, S. (2007). Differential regulation of IgG subclasses and IgE antimalarial antibody responses in complicated and uncomplicated Plasmodium falciparum malaria. Parasite Immunol. 29, 475-483.

Taylor, R. R., Allen, S. J., Grenwood, B. M., and Riley, E. M. (1998). IgG3 antibodies to Plasmodium falciparum merozoite surface protein 2 (MSP2): increasing prevalence with age and association with clinical immunity to malaria. Am. J. Trop. Med. Hyg. 58, 406-413.

Troye-Blomberg, M., Berzins, K., and Perlmann, P. (1994). T-cell control of immunity to asexual blood stages of the malaria parasite. Crit. Rev. Immunol. 14, 131-155.

Troye-Blomberg, M., Perlmann, P., Nilsson, M., and Perlmann, H. (1999).
Immune regulation of protection and pathogenesis in Plasmodium falciparum malaria. Parassitologia 41, 131-138.

Verra, F., Luoni, G., Calissano, C., Troye-Blomberg, M., Perlmann, P., Perlmann, H., Arcà, B., Sirima, B. S., Konaté, A., Coluzzi, M., Kwiatkowski, D., and Modiano, D. (2004). IL4-589C/T polymorphism and IgE levels in severe malaria. Acta Trop. 90, 205-209.

Weidinger, S., Gieger, C., Rodriguez, E., Baurecht, H., Mempel, M., Klopp, N., Gohlke, H., Wagenpfeil, S., Ollert, M., Ring, J., Behrendt, H., Heinrich, J., Novak, N., Bieber, T., Krämer, U., Berdel, D., von Berg, A., Bauer, C. P., Herbarth, O., Koletzko, S., Prokisch, H., Mehta, D., Meitinger, T., Depner, M., von Mutius, E., Liang, L., Moffatt, M., Cookson, W., Kabesch, M., Wichmann, H. E., and Illig, T. (2008). Genome-wide scan on total serum IgE levels identifies FCER1A as novel susceptibility locus. PLoS Genet. 8, e1000166. doi:10.1371/journal.pgen.1000166

Yabuki, M., Fujii, M. M., and Maizels, N. (2005). The MRE11-RAD50-NBS1 complex accelerates somatic hypermutation and gene conversion of immunoglobulin variable regions. Nat. Immunol. 6, 730-736.

Conflict of Interest Statement: The authors declare that the research was conducted in the absence of any commercial or financial relationships that could be construed as a potential conflict of interest.

Received: 07 November 2011; accepted: 01 December 2011; published online: 23 December 2011.

Citation: Blank $U$ and Mécheri $S$ (2011) Duality and complexity of allergic type inflammatory mechanisms in determining the outcome of malaria disease. Front. Immun. 2:78. doi: 10.3389/fimmu.2011.00078

This article was submitted to Frontiers in Inflammation, a specialty of Frontiers in Immunology.

Copyright (c) 2011 Blank and Mécheri. This is an open-access article distributed under the terms of the Creative Commons Attribution Non Commercial License, which permits non-commercial use, distribution, and reproduction in other forums, provided the original authors and source are credited. 